\title{
Article \\ Comprehensive Analysis of Housing Estate Infrastructure in Relation to the Passability of Firefighting Equipment
}

\author{
Pavel Vrtal, Tomáš Kohout*(D), Jakub Nováček (D) and Zdeněk Svatý \\ Department of Forensic Experts in Transportation, Faculty of Transportation Sciences, CTU in Prague, \\ Konviktská 20, 11000 Prague, Czech Republic; vrtal@fd.cvut.cz (P.V.); jakub.novacek@fd.cvut.cz (J.N.); \\ svaty@fd.cvut.cz (Z.S.) \\ * Correspondence: kohout@fd.cvut.cz
}

Citation: Vrtal, P.; Kohout, T.;

Nováček, J.; Svatý, Z. Comprehensive Analysis of Housing Estate Infrastructure in Relation to the Passability of Firefighting Equipment. Appl. Sci. 2021, 11, 9587. https:// doi.org/10.3390/app11209587

Academic Editor: Leon Rothkrantz

Received: 9 September 2021

Accepted: 11 October 2021

Published: 14 October 202

Publisher's Note: MDPI stays neutral with regard to jurisdictional claims in published maps and institutional affiliations.

Copyright: (c) 2021 by the authors. Licensee MDPI, Basel, Switzerland. This article is an open access article distributed under the terms and conditions of the Creative Commons Attribution (CC BY) license (https:// creativecommons.org/licenses/by/ $4.0 /)$.

\begin{abstract}
The article focuses on the assessment and evaluation of the passability in densely populated parts of cities with multi-storey housing estates, in terms of the operation of the integrated rescue system (IRS) in the Czech Republic. The aim of the research is to minimize the arrival times to conduct the intervention as efficiently as possible. The presented problem is caused by unsystematic development of housing estates and the emergence of secondary problems in the form of inability to reach the place of intervention by the larger IRS vehicles. The vision presented in this document presents a systematic approach to improve the serviceability of individual blocks of flats. The main aim is to ensure passability, even for the largest equipment, such as fire engine ladders. Detailed mapping of the selected sites by drones, construction of their digital model, and subsequent virtual verification of the passability by specific vehicle models on identified access roads was performed. The results obtained by this procedure can then be implemented in the navigation of the fire safety forces and facilitate their arrival at the site of intervention. At the end, specific ways are presented in which the whole system can be modified to be able to intuitively change and choose individual access routes in real time, based on the current situation in the area.
\end{abstract}

Keywords: fire rescue service; smart cities; housing estates; swept paths; digital model

\section{Introduction}

The resilience of each city is determined by the level of risk management or the management of potential critical situations. In order to be effective in its function, the city itself must have the necessary comprehensive resilience to the potential threats, collapses, or functional limitations. One of the most important aspects of any city is the provision of transport infrastructure for the operation of the IRS. Specifically, this involves ensuring accessibility in densely populated areas of the city with high-rise prefabricated housing [1].

The history of housing estates in the Czech Republic varied and the architectural character of these localities has evolved considerably over the years. From an urban, architectural, and technical point of view, the largest problems are presented by the largerscale housing estates. These were built mainly in the 1970s and 1980s and were almost exclusively constructed with prefabricated apartment buildings. An example is Prague, the capital of the Czech Republic. There are more than 600,000 flats in apartment buildings, in which almost $90 \%$ of the population of the capital city lives [2]. At the same time, the available statistics [3] show that almost half of Prague's population is concentrated in housing estates. There are currently 16 housing estates on the territory of the capital city with at least 10,000 inhabitants. Such large housing estates pose a number of traffic and transport challenges that are not currently thoroughly solved [1].

If we look at the housing estate as a system, it is possible to notice its gradual and continuous development, which in many aspects can be seen as a positive change (development according to the needs of residents), but also in many aspects as a negative one (unsystematic reconstruction of the area, and deviation from the originally intended 
transport and pedestrian links). The increasing level of motorization, and with it the ever-increasing demand for parking spaces [1,4], are not insignificant factors. For this reason, traffic at rest is accumulating in places that are not allocated for this purpose in the first place. Typical examples include inappropriate parking at crossroads, at the mouth of slip roads, or where parking is prohibited by traffic signs. Inappropriate parking reduces the efficiency of the transport links in the area and not only significantly reduces the traffic service but also worsens the safety and accessibility of the area.

The inappropriate construction layout of the area, together with the violation of road traffic rules, generates a significant problem, namely, the restriction of the passage of the IRS units during the intervention. Significant is the deterioration in time efficiency during passage through the area; thus, a delayed possibility of rapid intervention. These problems mostly affect the Fire Rescue Service (FRS), which has the largest vehicles within the IRS fleet. The length of fire tankers is almost $10 \mathrm{~m}$, and in the case of a fire engine ladder truck, the vehicle is more than $10 \mathrm{~m}$ long $[5,6]$. Removing obstacles or finding an alternative detour route leads to significant time delays, which consequently results in increased risks to the person in danger or damage to the corresponding property.

The purpose of this article is to present an approach that can be used to solve the most important problems that limit the movement of the FRS through existing residential areas and then to point out the most important aspects that must be taken into account for a systematic evaluation. By applying once-off area-based data collection, it is possible to build a digital model of the area in which the quality of individual access roads can be assessed. On the basis of this analysis, it is possible to define a scheme of the key emergency routes along which the time losses are minimised and the passability of the FRS vehicles is ensured. Finding the most suitable access routes to each high-rise building allows the most effective and safe intervention. Additionally, effectivity can be increased by implementing the findings in the currently used software platforms by the FRS, e.g., dispatch and navigation [7]. A secondary objective is to provide examples of how to modify the whole clearance assessment approach using modern technologies in such a way that it can operate online in the future and intuitively assess risks in real time.

In the following chapters, current methods and procedures related to the passage of the FRS vehicles in urban areas and the methods aimed at mutual communication of the intervening vehicles are discussed. Furthermore, the methods used in the analysis of area in close proximity to the intervention target are discussed, followed by specific examples, justification, and the outputs of a pilot project. The next part is focused mainly on the visualization and creation of models related to the FRS ladders and their subsequent application in the search for the optimal solution within the area. The paper concludes with suitable methods to support procedure automatization in the course of the following years. The following paragraphs describe the research method of the proposed project.

- Primary inputs: The motivation for the research was an impulse from the FRS, which has long struggled with the issue of the passability through housing estates by FRS vehicles. Due to the fact that this is a pressing and socially important issue, a working group was formed with experts from both the academic and practical sector. Among others, the aims of the research are the creation of a comprehensive methodological procedure for a complex analysis of housing estates in terms of the serviceability by FRS vehicles, to provide a definition of the appropriate procedures and methods for these analyses, and identification of the corresponding remediation measures.

- Dataset extension: In order to set up a suitable mechanism for the procedure of the research process, it was necessary to determine the methods that can be used to obtain a representative data set, which will then be subjected to detailed analyses. Closely related to this was the choice of appropriate measurement equipment and software to enable the collection of relevant data, their interpretation and analysis, operations with these data, and subsequent validation of the proposed solutions. At the same time, it is essential to choose methods and measuring instruments that can be potentially used in any location. 
- Relations and model definition: In the next phase, the hypothesis for the specific outputs was defined. This involves the interpretation and analysis of the data obtained, defining the key parameters affecting the resilience of the housing estates accessibility in the research area.

- Outputs: The main objective of this research is to set up a suitable methodology for a comprehensive analysis of FRS vehicle passability in housing estates together with determination of the corresponding remedial measures. However, due to the complexity of the issue, it is also necessary to define the roles and steps for various involved stakeholders.

\section{The Current Approach}

The current approach to the problem of firefighting vehicles throughput, route planning, or effective arrival times focuses primarily on the routes between the fire station and the general area near the location of the fire. Several scientific publications have dealt with this topic, and several of them are summarised in the following paragraphs. Notable is a publication from the city of Changsha (China) [8,9] that is addressing the arrival times of firefighting units within the city. The premise in this study is that at least one fire tanker and one fire ladder truck should arrive at a given location within $240 \mathrm{~s}$ of a fire being detected. However, problems caused by congestion and a low density of fire stations in city centres make this assumption very difficult.

A similar approach was applied in the city of Nanjing (China) [10] in a study to verify the accessibility of different parts of the city in relation to the effective travel times of existing fire stations. The assessment of the suitability of fire station locations and their time of accessibility to the fire scene was analysed using the FC2SFCA method, which focuses on specifically defining the service boundary from each fire station and determining from which stations it is appropriate to lead the response to different parts of the city. The paper furthermore describes the comparison of the previously mentioned method with the older E2SFCA method and assesses the differences and precision of each procedure. The method shows that the coverage near fire stations or in the city peripheries is far more effective than coverage in the city centre, where high traffic density is a particular problem.

Publications from Pennsylvania State University (USA) [11] discuss the arrival times to the location of an incident together with a main focus on the impacts and economic losses associated with the time lost by the emergency services in reaching the fire location due to traffic congestion.

Other research related to integrated emergency services [12] is concerned with improving the efficiency of passage through light-controlled intersections, where emergency vehicles share their positional information with traffic lights. Research conducted in Saudi Arabia uses a mobile application that links the vehicle data with map data and the traffic light sensors. In the event that an IRS vehicle arrives at a traffic light, the vehicle's lane switch to the clear phase. In this way, traffic from other traffic directions does not accumulate at the crossroads and the traffic flow is smooth, without significant delays.

Research at Bangladesh University [13] focused on dynamic changes in the signal depending on the current position of the IRS vehicles. The proposed system works on a cloud centric Internet of Things (IoT) principle. It collects information about the location of vehicles and signals at traffic-light-controlled crossroads. The acquired information is evaluated, and the system subsequently changes the phases on the traffic lights to enable a priority pass-through of the IRS vehicles.

Another research study was trying to achieve similar results by solving crossing problems using a complex RFID-based system [14]. The system is designed to be able to detect both image and sound from the IRS vehicles and thus be able to change the order of phases at light-controlled intersections. This enables to the IRS vehicles an easier crossing of these incriminated points.

The research projects also aim to address the interaction between vehicles and their environment. A paper published by the University of Žilina (Slovakia) [15] presents 
cooperation between individual vehicles and sensor data, helping to increase the safety and improve the communication skills of individual road users. The use of vehicle-tovehicle (V2V) and vehicle-to-everything (V2X) methods is intended to help warn drivers of approaching emergency services in time to create space for mutually safe crossing.

It could also be mentioned that there is a research focused on modelling buildings and their subsequent servicing by firefighting vehicles. Research from the National Central University of Taiwan [16] focuses on simulating fires on individual floors of high-rise buildings and their subsequent firefighting strategies. The proposed method involved the exploration of a 3D geometric network model (GNM) based on a building information model (BIM) to simulate firefighting. The operation of firefighting ladders during a response was also simulated in a 3D virtual environment. Finding the ideal location for the fire trucks to stop was supported by a methodology that can be used to determine the ideal location of the truck placement before the actual arrival of the engine in the fire area. At the same time, future research considers the use of real-time traffic sensors data to predict traffic conditions and adapt the optimal routing of the intervention line.

Similarly to the abovementioned strategy of deploying fire trucks around burning buildings, the research published by Belgian, Dutch, and Chinese academics [17] focuses primarily on water refilling of fire trucks in the process of fighting oil fires. The procedure uses the eM-plant simulation tool to model the firefighting process. In the context of the so-called chemical accident and to prevent its escalation, strategies are also considered to allocate fire trucks according to the distance from the hydrants and to divide fire trucks according to their number.

Improving the strategy of serving a given area is also discussed in a publication from the Netherlands [18]; it aims towards the optimisation of the allocation of firefighting vehicles to the location of an accident from the perspective of the emergency control room, based on historical dispatching problems where multiple vehicles from different locations are dispatched to the location of an incident and a decision has to be made as to which fire engine will be on site first. In this paper, a method to dispatch fire trucks is described in a way that strikes the right balance between rapid response to the actual fire and also good coverage of any simulated incidents.

After reviewing the currently available publications, it can be concluded that areas in close proximity to the actual intervention site are not being addressed in greater detail. However, these areas may have the highest loss times when the IRS vehicle is not able to access the actual location of the intervention. Currently, the intervention of the IRS forces is guided by the fastest possible route to the place of the critical accident, but without any knowledge of the actual situation in the target area. The innovation of the presented concept lies in the application and combination of knowledge from the Road Safety Audit (RSA), new methods of detail analysis of the area, especially by using aerial photogrammetry, and subsequent simulation in a virtual environment.

\section{The New Approach}

To further elaborate and verify the abovementioned conclusions, a pilot project in cooperation between the CTU in Prague, Faculty of Transportation Sciences, and the Prague 11-Chodov district was carried out. This project enabled the conversion of the theoretical intentions related to the solution of housing estates from the perspective of the passage of the FRS into real practice. This project has also enabled to define a methodological procedure that contains generalised guidelines to implement proposed solution in other localities. Figure 1 below shows the generalised steps of the procedure. The aim is to meet all the input requirements raised by the IRS units and local municipalities and to minimise any adverse effects on the residential needs. Marked boundaries around the steps, either solid or dashed, represents their nature. While the parameters marked with solid lines are determined and defined once during the evaluation. The dashed marked are iteratively adjusted over time in relation to the actual situation and development within the target area. 


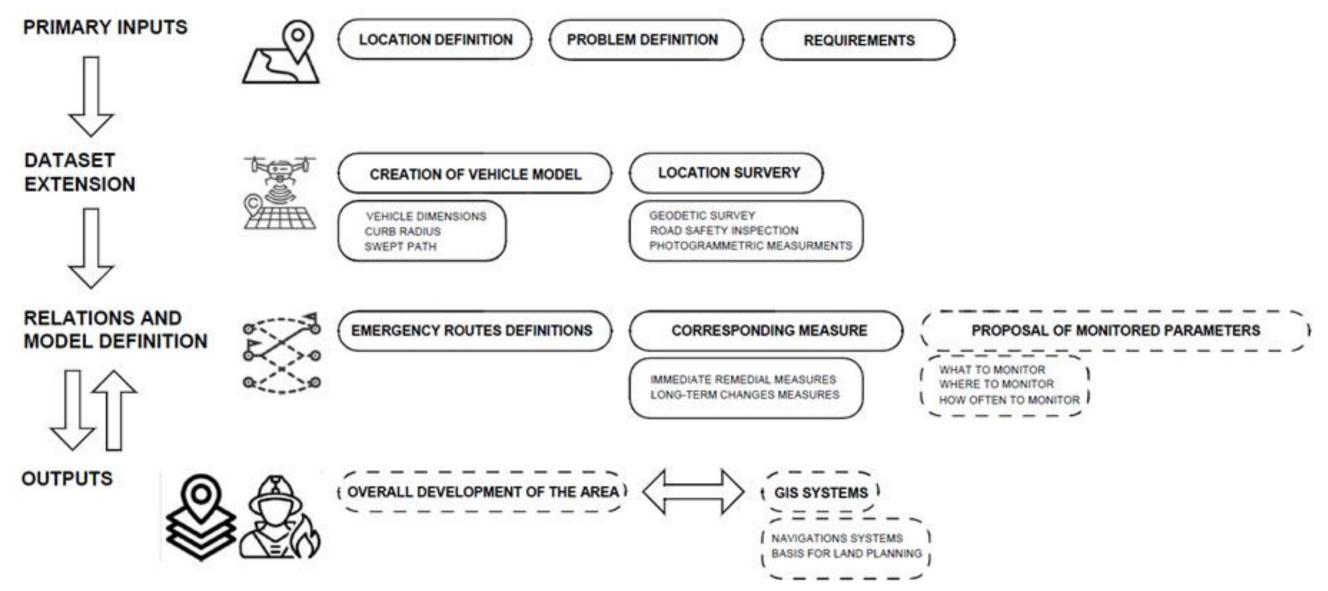

Figure 1. Diagram of the generalised procedure steps.

The target objective of the current project was to create a simplified offline digital model of the location, in which it would be possible to verify and evaluate the operation of the IRS during fire or other emergency situation. In the context of interaction between the FRS dispatching centre and the FRS commanders, this method can be used to prevent traffic complications caused in areas in close proximity to the target site and to avoid an increased arrival time due to inappropriately chosen routes for intervention.

\subsection{Primary Inputs}

In the beginning, it was necessary to assess all aspects related to the target area. Specifically, this involved assessment of the location and its relations within the town, identification of the key roads, and evaluation of their significance on the rest of the surrounding area. Additionally, it was necessary to define the appropriate crossings with the surrounding parent road network for the initial arrival of firefighting equipment. Linked to this is the necessity to assess the impact of traffic volumes on these roads, traffic flow mix, and junction capacity. These present an important factor that influences the initial choice of routes for intervention into the area. Furthermore, the assessment of the area from the point of view of the resident's demands was performed. The aim was to minimise the interference with the existing capacity of parking areas and at the same time with areas intended for leisure activities (parks and playgrounds). Lastly, it is necessary to consider the experience of the firefighters who serve the area, as they are aware of the most significant issues that limit the passage of their equipment.

\subsection{Dataset Extension}

In order to create a sufficiently detailed digital model of the area and to enable verification and simulation of the passability, low altitude aerial photogrammetry with a drone was used. The primary objective of the measurements was to obtain a digital three-dimensional spatial model with sufficient accuracy and detail. In contrast to classical measurement methods, the digital image correlation method was used, to facilitate the speed of data acquisition and processing [19]. The advantage of its application is that it does not require the explicit identification of individual points but uses image recognition algorithms to automatically identify the key features among the images, link them, and subsequently reconstruct the spatial information. Firstly, the Structure from Motion technique (SfM) was utilized. The SfM method uses a number of unordered images that depicts a static scene or an object from arbitrary viewpoints and attempts to recover camera parameters and a sparse point cloud that represents the 3D geometry of a scene [20]. The second stage consists of a further reconstruction of the geometric scene. This was carried by the Dense Multi-View 3D Reconstruction algorithm (DMVR), which was run on an already-aligned image set. The algorithm operates on a pixel base, thus enabling it to obtain a higher level of detail than the SfM [20]. The scale, transformation, and validation of the resulting model 
were performed with signalised points measured with the GNSS station. The resulting accuracy was $2.5 \mathrm{~cm}$ in position $(X, Y)$ and $3 \mathrm{~cm}$ in height $(Z)$. In this way, the resulting model was aligned with cadastral maps and it was possible to clearly define individual parcels intended for potential remediation. Figure 2 show a part of the assessed area in which the pilot project was carried out. Figure 2 depicts positions of captured images (over 3000 photographs were taken) together with the necessary overlap for successful reconstruction. Blue areas that are represented with the highest frequency represent the highest overlap of each image. The number of overlapping images then decreases to lower values in the extreme areas of the site. At the same time, the figure below also shows the statistics of the performed measurements.

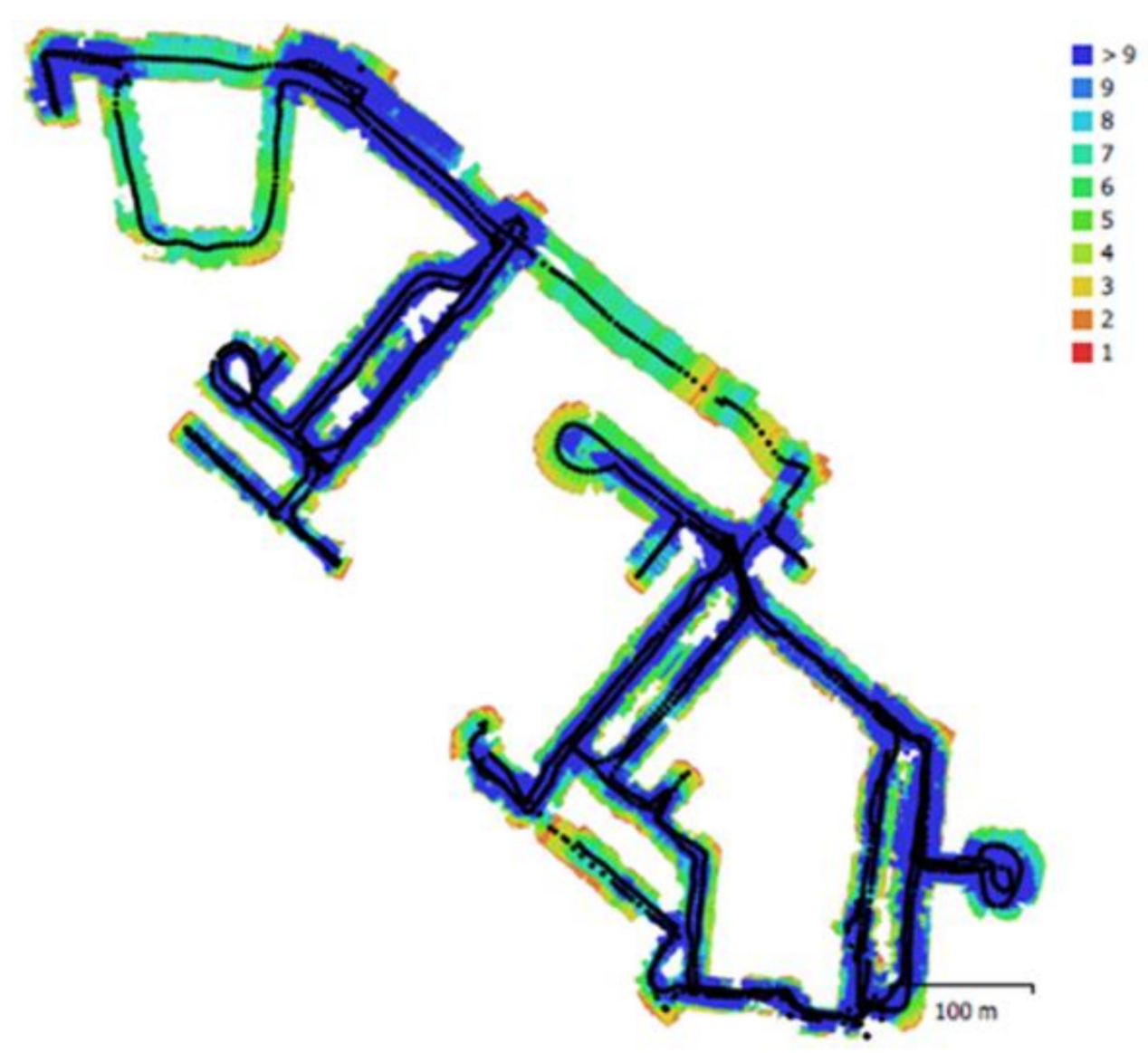

$\begin{array}{llll}\text { Number of images: } & 2313 & \text { Camera stations: } & 2305 \\ \text { Flying altitude: } & 22.1 \mathrm{~m} & \text { Tie points: } & 5,297,607 \\ \text { Ground resolution: } & 6.72 \mathrm{~mm} / \mathrm{pix} & \text { Projections: } & 15,307,379 \\ \text { Coverage area: } & 0.107 \mathrm{~km}^{2} & \text { Reprojection error: } & 0.837 \mathrm{pix}\end{array}$

Figure 2. Camera locations and image overlap with parameters.

The photogrammetric outputs are similar to laser scanning but with significantly lower time demands and corresponding costs, and only a slightly lower accuracy (RMS of $2.1 \mathrm{~cm}$ ). For the purposes of this study, a textured triangular polygon mesh of the area was created together with a detailed orthophoto with a resolution of $2 \mathrm{~cm} / \mathrm{px}[19,20]$. Such detail is essential, especially in places where road width ratios reach very small values that border on the minimal required passage profile of the FRS vehicles.

The advantage of this approach is also the fact that the resulting model corresponds to the current situation at the time of measurement, e.g., shows parked vehicles, dustbin placements, fences, etc. Furthermore, it is complemented by the textures of the environment 
for effective presentation and orientation; therefore, it tells about the actuality and related deficiencies much more accurately than could be obtained from a panorama view, satellite imagery, or classical aerial maps.

In order to assess the passability, it is not necessary to work directly with a 3D model of the environment. The initial site analysis can be performed on a 2D basis (sufficiently detailed orthophoto is available). However, the use of a 3D model is necessary for evaluation of the clearance at locations where there are features that restrict the clearance profile of fire engines. These elements are, for example, unmaintained vegetation, road signs, streetlights, or bridge structures.

An illustration of the digital model is presented in Figures 3 and 4. Figure 3 shows the resulting spatial model, mesh, together with the location of each captured image. This presents a significant advantage due to the possibility to easily retrieve detailed photographs of the selected area during the subsequent analysis. Figure 4 shows the same model with textures.

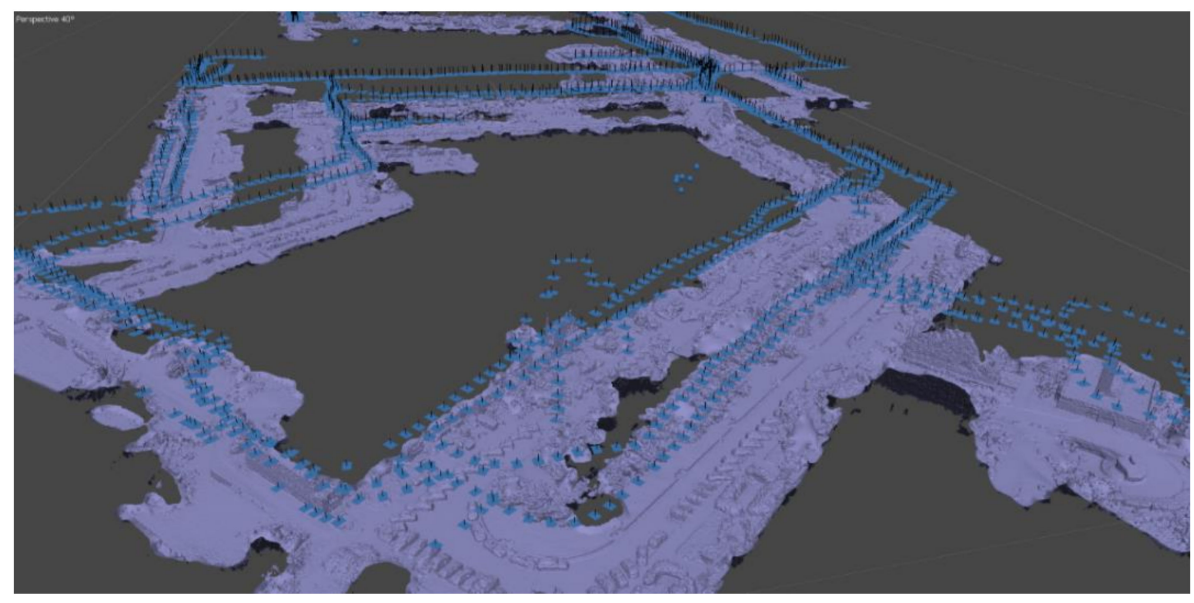

Figure 3. Digital model of the area with individual images.

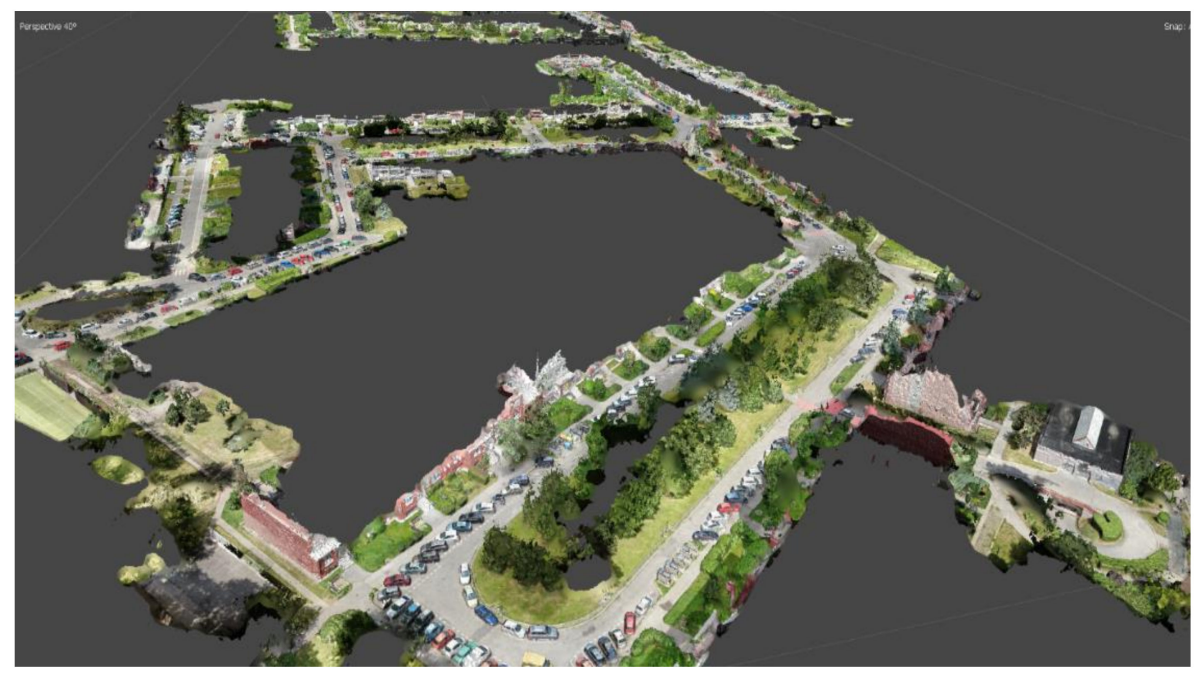

Figure 4. Digital model of the area with textures.

Another way to expand the input of the evaluated area was through implementation of the RSA principles. The site inspection enables to detect potential critical locations and problems that might not be apparent at first look from the digital model or to somebody without traffic safety knowledge. Examples include high kerb edges at the entrances to emergency routes that could be used by the FRS, inadequate placement of road signs, or traffic-related safety issues. 
Due to the specific geometric requirements of the FRS equipment, especially fire engine ladder trucks, which have the highest spatial demands, it is necessary to evaluate the passability of the vehicle through the area for the purposes of optimal intervention routes. Furthermore, the passability assessment enables verification of the efficiency of the selected routes. The passability can be easily verified with use of specialized swept path software. However, since almost every firefighting vehicle is unique in its parameters and differs from factory vehicles, the general vehicle data sheets cannot be used without adjustments. The same issue is with use of the predefined models designed for the verification of passability. A typical example of limited applicability of using already constructed models is the fact that each vehicle has different additional equipment, e.g., in the form of a pull-out ladder or a rescue basket. On the other hand, the basic precondition is that the high-rise firefighting equipment serving the area remains unchanged for several years (15-25 years). Therefore, the assessment or proposed changes can be related to the demands of specific fire vehicles that are serving the evaluated area.

As a result of incomplete technical documentation of the fire engine ladder truck used in the project (affected by the unique accessories mentioned above), it was necessary to create a model for subsequent simulations. A wide range of measuring methods can be effectively used to collect the data concerning the car body, its add-on components, and its dynamic characteristics, e.g., curb radius. The combination of the above-obtained parameters can then be suitably used in the creation of digital models, which can then be used to construct swept paths to verify the passability of the site under consideration. The chosen reference vehicle is shown in Figure 5.

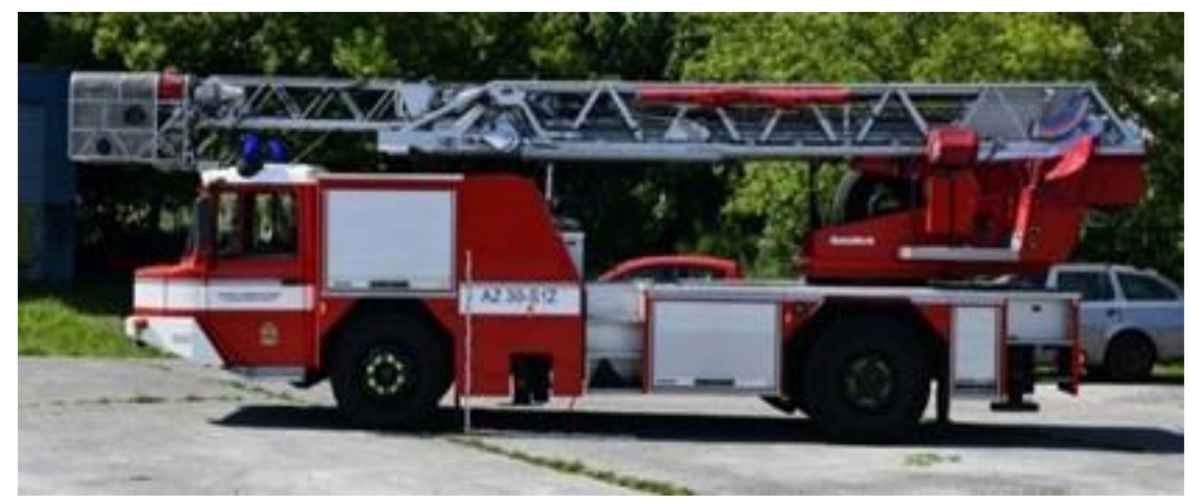

Figure 5. Photo of a fire engine ladder truck $[5,6]$.

\subsection{Relations and Model Definition}

The standardised vehicle models and freely available vehicle databases very often represent an idealized vehicle, which in its dimensions covers approximately $85 \%$ of the fleet of the same or similar type of vehicle or vehicles defined by national standards [21]. Common practice for passability assessments is to use the garbage truck model. However, due to significant differences in the dimensions and characteristics of the vehicle swept path during cornering, this leads to a situation where the vehicles that play the most crucial role in saving lives are omitted. Therefore, during the project, a simplified model of an FRS ladder truck was created and subsequently used to the assessment. Figure 6 shows the resulting simplified model defined in the AutoCad Vehicle Tracking software. For the purposes of model creation, it was necessary to determine not only the characteristic dimensions of the vehicle but also the actual turning radius, wheel angle, etc. The characteristic dimensions were determined with photogrammetric and geodetic measurements. Figure 7 shows the captured images of the ladder truck, reconstructed spatial model, and dimensions of the selected parts of the truck (length, height, ladder dimensions, etc.). 




Figure 6. Final digital model of a fire engine ladder truck created in AutoCad Vehicle Tracking.

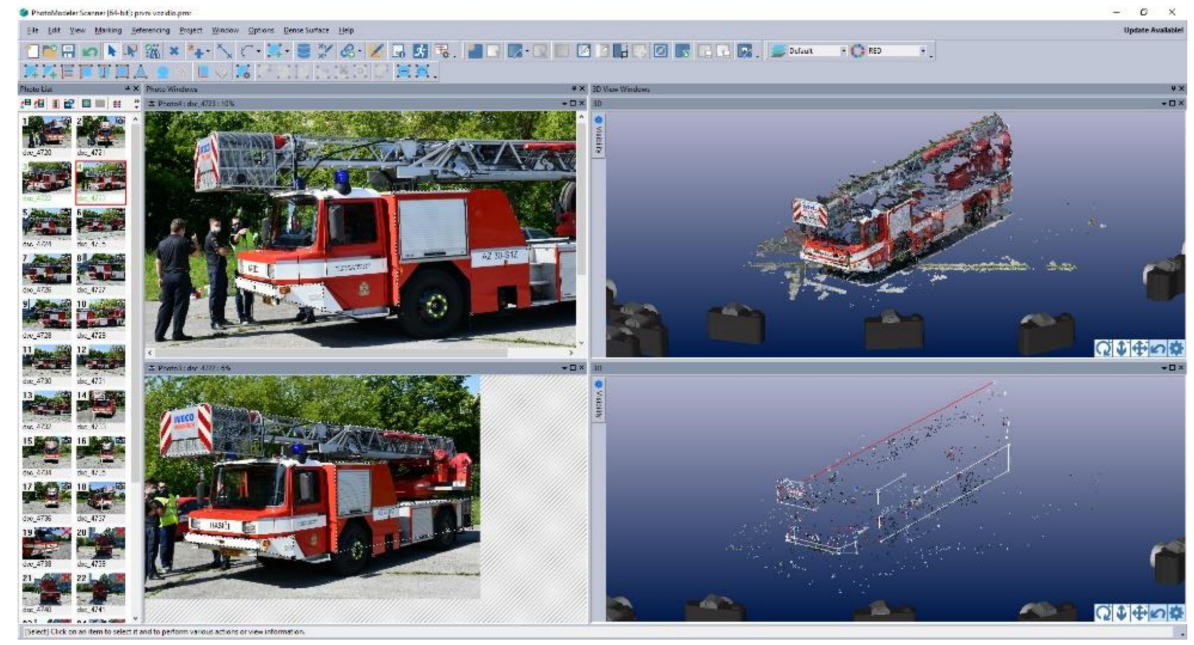

Figure 7. Photogrammetric measurements of the characteristic dimensions of the FRS ladder truck in Photomodeler Scanner.

Figure 8 shows the differences between the garbage truck model and FRS ladder truck.
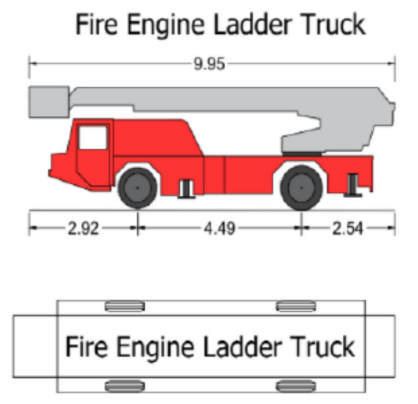

Small Truck (Garbage Truck)

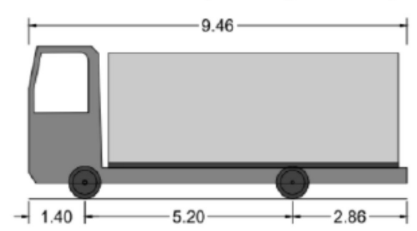

Small Truck (Garbage Truck)
Overall Length

Overall Width

Overall Body Height

Front Overhang

Wheelbase

Rear Overhang

Minimum Height Clearence

Turning Time Between Full Runs

Turning Radius Between Kerbs
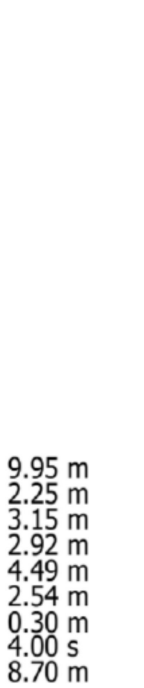

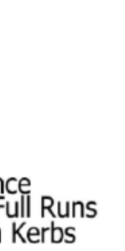

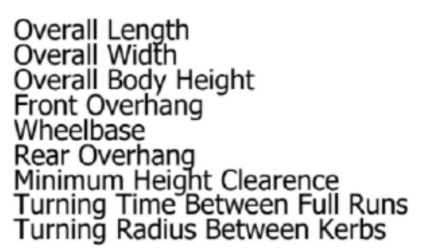

Overall Width

Overall Body Height

Front Overhang

Rear Overhan

Turning Time Between Full Runs

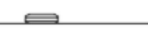

Figure 8. Technical parameters of the fire engine ladder truck and the garbage truck.

In order to obtain a real swept path of the reference FRS vehicle, a research experiment was conducted with an FRS vehicle (Figure 9). In this experiment, the full turn of the FRS vehicle at maximum wheel travel was monitored by drone. The speed of the vehicle was determined based on the FRS experience at approx. $5-10 \mathrm{~km} / \mathrm{h}$. The footage was subsequently rectified to enable direct identification of wheels trajectory and the vehicle contours. Thus, it was possible to determine the actual turning radius and wheel angle. 


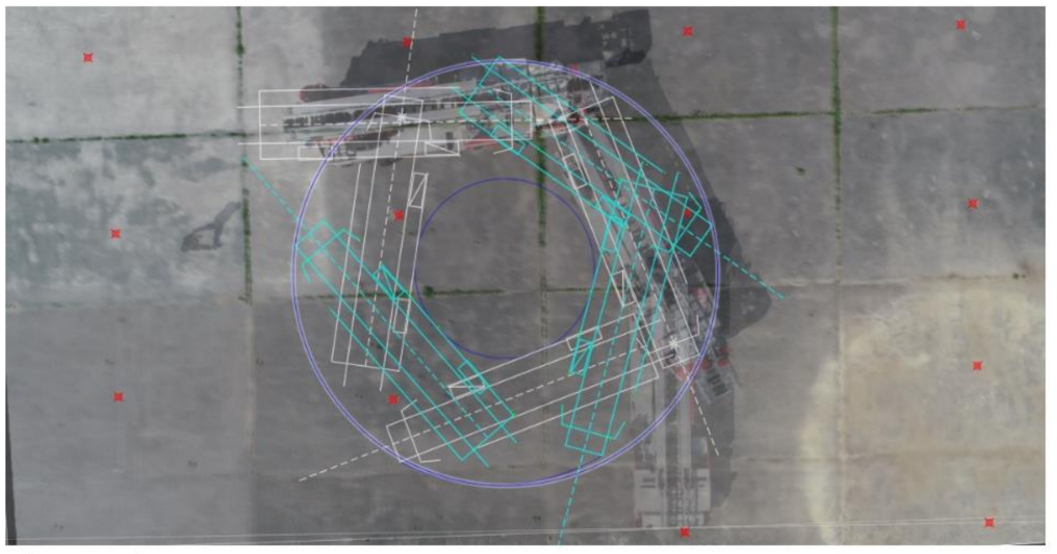

Legend:

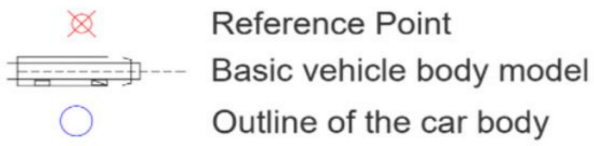

Figure 9. An example of a calibration experiment of the swept path for vehicle model design.

Ackermann's steering geometry was subsequently used for verification of the model validity, specifically by calculating the steering angle. The principle is based on a fixed axle where only the wheels rotate and is shown in Figure 10 [22].

$$
\begin{aligned}
& \alpha_{i}=\tan ^{-1}\left(\frac{L}{R-\frac{T}{2}}\right) \\
& \alpha_{0}=\tan ^{-1}\left(\frac{L}{R+\frac{T}{2}}\right)
\end{aligned}
$$

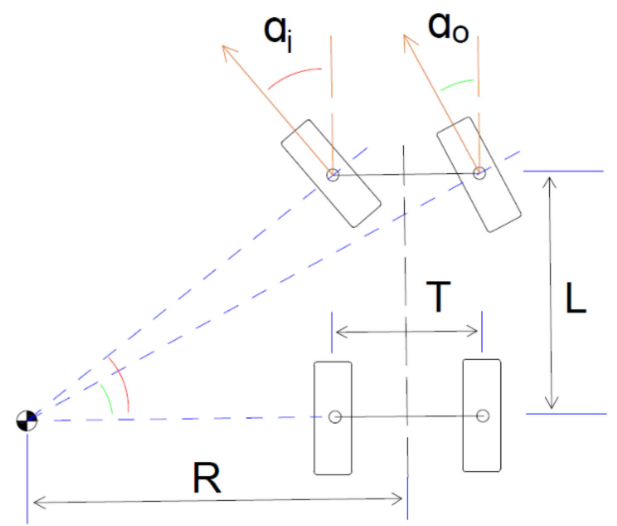

Figure 10. Ackermann's steering geometry [22].

By substituting the observed turning radius into the equation, a value for the wheel angle was obtained and compared with the experimentally measured value for the wheel angle. This verified that the determined vehicle turning radius corresponded to the real vehicle.

The resulting simplified model showed that vehicles that are very similar to firefighting vehicles in terms of their parameters (length, width, and height) actually have significantly different trajectories. Figure 11 shows a comparison of the swept paths of a municipal waste vehicle (blue) and a fire engine ladder truck (red). This difference in their manoeuvrability is closely related to the different turning radius or steering angle of the wheels. The different behaviour can be seen especially in the initial phase of the turning manoeuvre, due to the greater body overhang of the fire engine ladder truck compared to a conventional truck. 




Figure 11. Swept paths of the fire engine ladder truck and garbage truck.

By using digital models of firefighting equipment and a digital model of the area, it was possible to verify the passage through the selected area in the current layout; this enabled to define the critical locations where potential bottlenecks may occur and which require subsequent structural modifications. These basic outputs became the basis for subsequent comprehensive research outputs. The most frequent problems affecting the passability are high kerb lines, which cannot be driven over into the vicinity of buildings; incorrectly implemented parking places, which interfere with the crossroad areas; inappropriately placed vertical traffic signs, which prevent parking of vehicles with the overlap of the bow onto the pavement; or inappropriately placed solid obstacles, e.g., concrete posts, railings, etc. The main objective is to eliminate the identified problems as soon as possible. Priority is given to problems that can be solved easily, at a low cost, or with low corresponding administration. However, the general idea is that the measures must be performed systematically and in coordination between all involved partners.

Most prefabricated buildings in the area have several possibilities from which a rescue operation can be performed, but not all roads are suitable for the passage of larger firefighting equipment, e.g., spatial or load limitations. The most efficient solution logically seems to be the use of roads that were designed to enable firefighting operations at the time the area development. However, there are cases when during time the purpose of these roads changed, some of the connections disappeared, or parts of them are currently used for different purposes than the one for which they were originally established. Examples include the creation of parking places, flower gardens, partial or total redesign, etc. Despite this fact, these roads can still serve as a basis for the area serviceability.

Based on the available infrastructure in the evaluated area, several options were proposed to ensure the accessibility of every individual building in the project. At the same time, it was possible to determine the theoretical time delays of the individual intervention routes depending on the travel time to each location. Figure 12 illustrates the serviceability options for the area and the design of the main or alternative emergency route. Furthermore, this solution identifies the locations where it is possible to perform only a one-way passthrough or where it is possible to turn around or pass another vehicle. The digital model also provides information about the vertical distance of the road from the face of the building. This distance significantly influences the overall reach of the fire 
ladders during an intervention and thus the course of the actions. It is essential to always find an area in front of the building where the distance is as small as possible, but at the same time, the area is wide enough to allow the support legs of the vehicle to be extended as far as possible to achieve the required stability and is able to withstand the load of the vehicle.

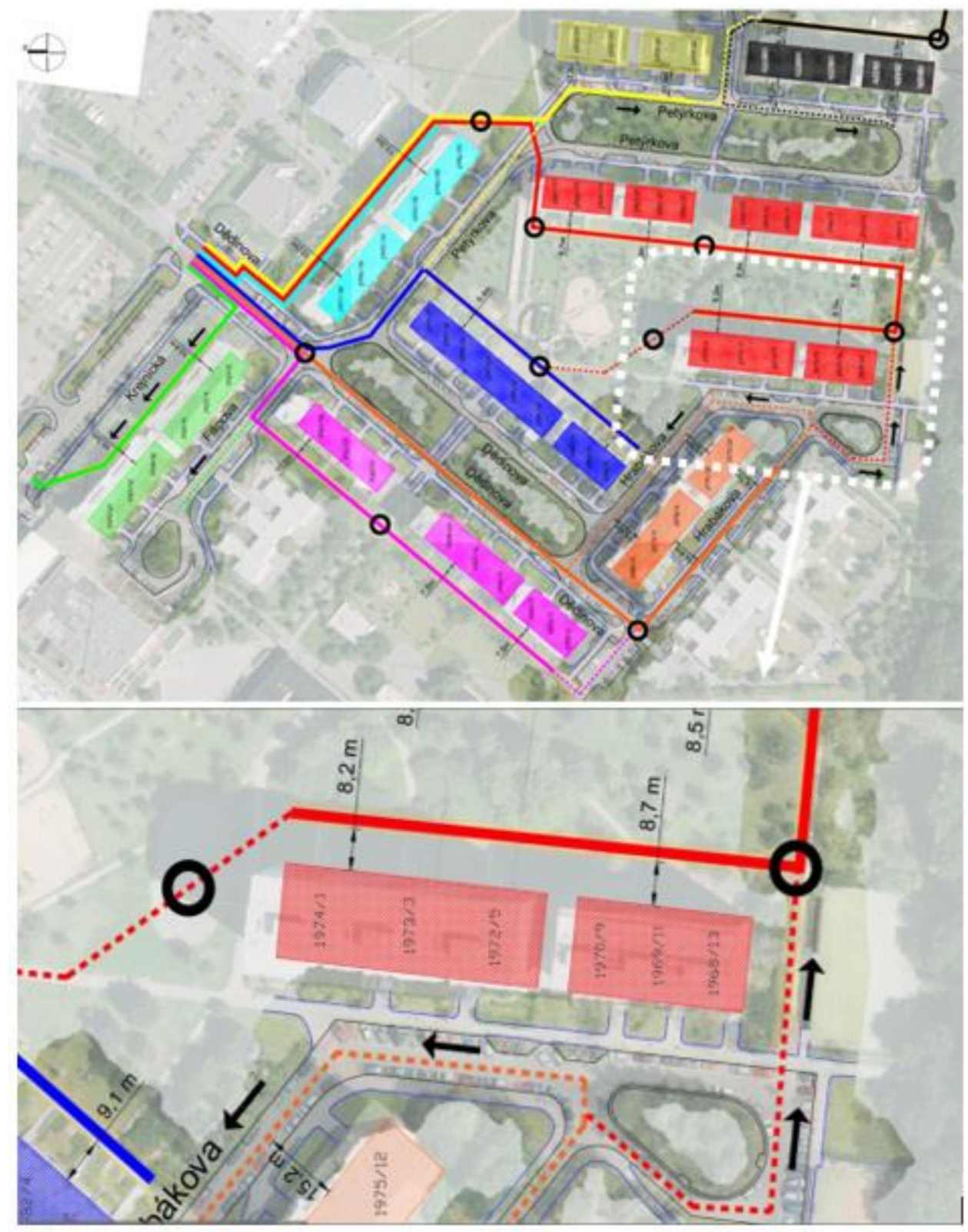

LEGEND:

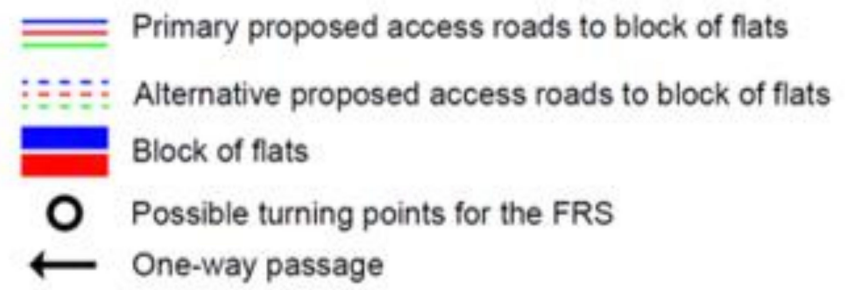

Figure 12. Schematic representation of the serviceability proposal for the evaluated area together with details of the selected area. 
Each entrance road to a particular block of flats has different loss times and different levels of complications depending on the occupancy of the roads by parked vehicles. For this reason, it can be presumed that time losses of an intervention vary during the day and directly correspond with the actual situation. During working hours, when most of the residents are away from their homes, the time-losses are lower in comparison to the evening, when parking capacity is considerably saturated and vehicles are parked even in places not set up for this purpose. For this reason, it is desirable to supply and accordingly modify the proposed emergency routes with online information, e.g., in the form of camera footage or by using data from traffic sensors. The advantage of the proposed approach is that the potential bottlenecks or critical locations can be determined in advance. Thus, the monitoring is designed with consideration of the specifics of the evaluated area. This leads to the possibility to select the most appropriate access route to individual buildings in a significantly more effective way than through a simple empirical experience.

\subsection{The Validation of Proposal and Project Outputs}

A mathematical description of the presented problem of FRS passability through housing estates can be determined by two basic premises. The first premise is the attempt to minimize the time of arrival of the FRS to the location of the fire, similarly as in case of optimization of serviceability of larger areas. The second premise works with the hypothesis of maximisation of the sum of probabilities for effective FRS intervention, such as maximisation of the probability of collision-free passage through the area in such a way that there are no elements limiting passage along the route, such as the spatial layout of the roads. Minimalisation is the probability that potential traffic excess in the form of a bottleneck will occur on the determined access route. The third factor is the probability of effective intervention directly at the place affected by the fire in terms of the technological possibilities of FRS vehicles. This is in close relation to the specific parameters of the target building/object. Parameters such as the maximum possible height available by means of a fire truck ladder or the minimum perpendicular distance from the extinguished object must be considered here.

However, there is a significant difference between the optimization of serviceability of larger area, e.g., part of the city, and the blocks with high-rise buildings, where only few potential routes are possible, special infrastructure is already in place, and only few access points exist. Therefore, it is very difficult to perform specific mathematical verification of the proposed routes, as each FRS intervention is very unique and different complications may occur. It is only possible to obtain a theoretical verification, but this lacks many variables and the result is thus highly biased. The general verification procedure of the proposed changes is related to the experimental determination of the transit speed of each route. For this reason, it is necessary to perform control measurements directly in real traffic with specific cars. In the authors' opinion, a general mathematical prescription for verifying the passage of FRS vehicles through a specific location cannot be made explicit using a clearly defined mathematical apparatus. Each such passage is unique and is always influenced by a number of variable parameters.

The research found that the FRS may not be the only end-entities benefiting from the research. Other involved parties can benefit from the research and use this for the city's development and to increase its safety. One of the key users is the dispatch of the IRS, which can implement the information in the navigation of the emergency services based on the actual place of the emergency. At the same time, it enables to inform the responding units in advance about the current traffic situation, possible risks, or most effective access routes. With the help of the online digital model of the area, it is possible to provide reliable information about the state of the site, both in terms of traffic and the possibilities of the vehicle placement. At the same time, it is possible to provide information where it is possible to pass another vehicle or the most suitable places for staging fire trucks so that the intervention can be carried out from the closest possible distance. 
The identified service routes are also directly applicable to the fire truck crews. The Czech FRS is currently using a map-based application for localisation and best utilisation of the hydrants in the area of intervention. The services routes are prepared and implemented using GIS systems. This approach enables to add this information within the application to improve the information available to the fire truck crew. Furthermore, this approach also enables to have an up-to-date overview of the individual service routes in the area in case the monitoring system is active. A similar approach is reported in Portuguese research, which also implements a decision-making system in GIS applications for the crew of the FRS in order to reach the fire location as quickly as possible and thus reduce the consequences [23].

Last but not least, the GIS data can be used to inform the municipality administration about critical areas and suitable passage routes for the IRS. The benefit is a safe and systematic development of the area in the future, as it is known which roads are necessary or where the problems arise; also, it enables to mitigate potential disruption of links in the service of the IRS in cases of road closures.

\section{Discussion}

While the methodological procedures applied in the previous chapter can be modified to achieve a direct response to the actual situation in the locality, the practical implementation is limited in several ways. The changes outlined in this chapter summarise how to effectively supplement the digital model of the area and improve its serviceability based on online information.

The most important part of the project, which currently contains the most data, is the digital model of the location. To be able to talk about a real virtual copy, which is similar in its characteristics to the vision of the Twin City model [1], it is necessary to add elements and systems capable of real-time monitoring of the city's traffic processes thanks to sensors directly connected to this virtual model. This includes, for example, data from sensors used to calculate the current occupancy of parking places [1]. If it is clear that the capacity of the parking places is not fully utilised, there will most likely be no inappropriate parking of vehicles at crossroads and no significant disruption to the flow or throughput of traffic through the site. In the event that the parking capacity is fully occupied, inadequate parking can be expected even at locations that are crucial for passability of the IRS (crossroads, fire roads, etc.). In these cases, the use of camera monitoring and subsequent systematic control seems to be an ideal solution [24]. When monitoring a lot of similar locations, it is possible to use induction loops or detectors working on a similar principle as a support tool that automatically informs the control centre of a potential issue.

Another approach is the potential utilisation of drones, which can be effectively used for detailed and periodical analysis of the assessed locations in a very short time. Verification of critical places or areas could be done similarly to the small parcel delivery system introduced by Amazon in recent years. Figure 13 illustrates a docking station mounted on a lamppost to serve as both a take-off point, charging station, and a connection point for the dispatch centre controlling the area. The drones provide an ideal means to scan a selected area in a short time frame and send the acquired data to a central control station before the actual firefighting operation takes place. In this way, it would also be possible to optimise in advance the route option during the intervention, thus avoiding any significant time delays [8]. However, the possibility of using drones in built-up areas is limited. Currently, such a data collection option cannot be implemented, as legislation and data protection do not allow the use of drones over built-up areas [25,26]. 


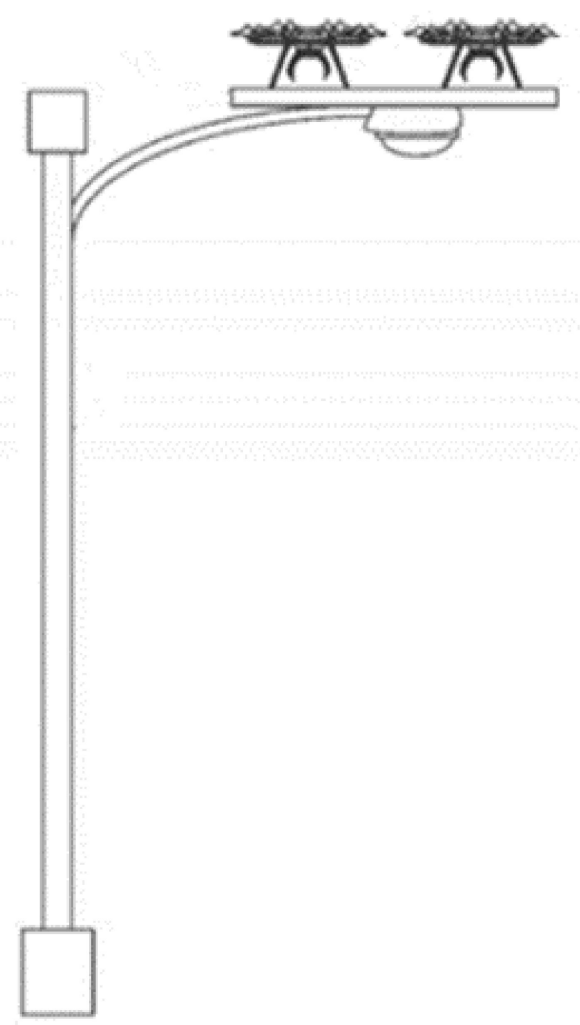

Figure 13. Drone docking stations on lamp posts [27].

Another way to obtain the necessary data for the assessment and analysis of selected locations can be through lidar or ultrasonic detectors. These can be mounted on garbage trucks that visit the sites several times a week. The collection of these data could be used to update the input data and to update the area model itself.

\section{Conclusions}

The effort to systematically evaluate the target areas of intervention in densely populated parts of cities with multi-storey housing estates has very specific goals-serviceability by the IRS, reduction of the arrival times of the IRS, and to enable the passage of large FRS vehicles. The research presented methods for obtaining the necessary data to evaluate the current condition of the locality and to design remediation measures. Primarily, these were the application of various photogrammetric and geodetic measurements to obtain outputs that were subsequently used for modelling in specialised software. This outlined a suitable procedure for mapping the locality and for obtaining the specific parameters of the FRS vehicles. This contribution presented a novel methodological approach that contains generalised guidelines for their practical implementation. The methodology enables to create a digital model of the location, in which it would be possible to verify and evaluate the operation of the IRS during fire or another emergency situation. Furthermore, the approach was validated through a pilot study in cooperation with municipal administration and the FRS. The pilot project has made it possible to consider all the specifics of the selected location and proposed a comprehensive solution in the form of a methodological procedure that can be used repeatedly for the analysis and subsequent design of measures for high-rise housing estates.

The new methodology approach of the area management also helps during the future development of the area, as it is possible to determine which roads or areas in the locality are crucial to ensure the serviceability by the IRS or which presents the highest risk or time delays. For this reason, it is also possible to plan a systematic remediation of the weak spots. The vision of the conceptual design was primarily to create a digital 3D model in which individual variants of the firefighting equipment's arrival to the intervention 
site can be simulated, verified, or tested, depending on the actual situation in the area. By integrating it into the current navigation systems used by the FRS, it is possible to optimise the arrival time and minimize the loss of life or the level of damage to properties. At the same time, the methodological approach presented by the research can be further developed by extension of the spectrum of the measured data or by implementation of other approaches to collect these data; for example, using sensors, camera surveillance systems, or detectors, as discussed in the previous chapter.

The safety and ideal serviceability of existing urban areas is a continual process, which needs to be periodically revised and improved due to the area development. It is essential to apply new procedures and use modern technological possibilities to facilitate the work of the emergency services to improve the resilience of the urban area in relation to the potential loss of life and property.

In this paper, we define approaches and methods for the comprehensive analysis of housing estates in terms of FRS vehicle passability. The paper presents a detailed outline of the scientific approach of each step of the proposed solution itself. We are aware that the problem addressed does not only affect housing estates in the Czech Republic but is a problem occurring worldwide. From a historical point of view, this problem is reasonably expected; for example, in all post-communist countries of Central and Eastern Europe, where in the past similar housing estates were constructed from uniform prefabricated materials. As a result of this conclusion, we believe that the presented approaches and methods, while performed only in the Czech Republic, and thus with consideration to its specifics, are applicable with only slight adjustments globally. This statement is also supported by the set of technological resources and software available to academics and professionals globally. This research and its outputs provide a clearly defined and unified set of methods applicable to the analysis of any housing estate across the world's countries.

Author Contributions: Conceptualization, P.V., T.K. and J.N.; methodology, P.V., T.K. and J.N.; software, P.V.; validation, P.V., T.K. and J.N.; formal analysis, P.V., T.K. and J.N.; investigation, T.K.; resources, P.V., T.K. and J.N.; data curation, J.N.; writing-original draft preparation, P.V. and T.K.; writing-review and editing, P.V., T.K. and J.N.; visualization, P.V. and Z.S.; supervision, P.V., T.K. and J.N.; project administration, P.V., T.K., J.N. and Z.S. All authors have read and agreed to the published version of the manuscript.

Funding: This research received no external funding.

Institutional Review Board Statement: Not applicable.

Informed Consent Statement: Not applicable.

Data Availability Statement: Not applicable.

Conflicts of Interest: The authors declare no conflict of interest.

\section{References}

1. Svítek, M.; Michal, P.; Votruba, Z.; Přibyl, O. Cities of the Future, 1st ed.; NADATUR: Prague, Czech Republic, 2018; ISBN 978-80-7270-058-5.

2. Czech Statistical Office. Housewives. 2011. Available online: https:/ /www.czso.cz/documents/10180/20567427/10413513k6 .pdf/95ecab47-9596-472b-8132-f75b023bcc42?version=1.0 (accessed on 15 July 2021).

3. Czech Statistical Office. Settlement Structure and Housing Type. 2011. Available online: https://www.czso.cz/documents/1018 0/20567443/42413513a2.pdf/c1bb081b-740e-405f-bd56-2a556d865123?version=1.0 (accessed on 15 July 2021).

4. Technical Road Administration. Transport Yearbook Prague 2020. 2020. Available online: https://www.tsk-praha.cz/static/udirocenka-2020-cz.pdf (accessed on 16 July 2021).

5. Kratochvíl, M.; Kratochvíl, V. Technical Equipment for Fire Protection, 1st ed.; Sdružení Požárního a Bezpečnostního Inženýrství: Prague, Czech Republic, 2009; ISBN 9788073850647.

6. Jendřišak, J.; Svoboda, P. Fire Trucks in Czech Republic, 1st ed.; FIJEPO: Prague, Czech Republic, 2005; ISBN 80-902705-4-9.

7. Systemflorian.cz. Available online: https://systemflorian.cz/ (accessed on 5 November 2020).

8. Liu, D.; Xu, Z.; Yan, L.; Wang, F. Applying real-time travel times to estimate fire service coverage rate for high-rise buildings. Appl. Sci. 2020, 10, 6632. [CrossRef] 
9. Liu, D.; Xu, Z.; Yan, L.; Fan, C. Dynamic estimation system for fire station service areas based on travel time data. Fire Saf. J. 2020, 118, 103238. Available online: https:/ /www.sciencedirect.com/science/article/pii/S0379711220307566?via\%3Dihub (accessed on 5 November 2020). [CrossRef]

10. Mao, K.; Chen, Y.; Wu, G.; Huang, J.; Yang, W.; Xia, Z. Measuring spatial accessibility of urban fire services using historical fire incidents in Nanjing, China. ISPRS Int. J. Geo-Inf. 2020, 9, 585. [CrossRef]

11. Daniel, B.; Louis-Philippe, B. Traffic congestion, transportation policies, and the performance of first responders, Pennsylvania, USA. J. Environ. Econ. Manag. 2020, 103, 102339. [CrossRef]

12. Almuraykhi, K.M.; Akhlaq, M. STLS: Smart Traffic Lights System for Emergency Response Vehicles. In Proceedings of the ICCIS 2019 International Conference on Computer and Information Sciences, Sakaka, Saudi Arabia, 3-4 April 2019; ISBN 978-1-5386-8125-1. [CrossRef]

13. Sangamesh, S.B.; Sanjay, D.H.; Meghana, S.; Thippeswamy, M.N. Advanced traffic signal control system for emergency vehicles, bangalore. IJRTE Int. J. Recent Technol. Eng. 2019, 8, 1242. Available online: https://www.ijrte.org/wp-content/uploads/papers/ v8i3/C4323098219.pdf (accessed on 5 November 2020).

14. Raman, A.; Kaushik, S.; Rao, K.R.; Moharir, M. A Hybrid Framework for Expediting Emergency Vehicle Movement on Indian Roads. In Proceedings of the 2nd International Conference on Innovative Mechanisms for Industry Applications (ICIMIA), Bangalore, India, 5-7 March 2020; pp. 459-464. Available online: https:/ /ieeexplore.ieee.org/document/9074933/ (accessed on 5 November 2020).

15. Jantošová, A.; Dolnák, I.; Dado, M. Cooperative and emergency services feasible in future vehicular networks, Žilina. In Proceedings of the ICECCE 2020 International Conference on Electrical, Communication, and Computer Engineering, Istanbul, Turkey, 12-13 June 2020; ISBN 978-1-7281-7116-6. Available online: https: / ieeexplore.ieee.org/document/9179485 (accessed on 5 November 2020).

16. Chen, L.C.; Wu, C.H.; Shen, T.S.; Chou, C.C. The application of geometric network models and building information models in geospatial environments for fire-fighting simulations, Taiwan. Comput. Environ. Urban Syst. 2014, 45, 1-12. [CrossRef]

17. Zhou, J.; Tu, C.; Reniers, G. Simulation analysis of fire truck scheduling strategies for fighting oil fires. J. Loss Prev. Process Ind. 2020, 67, 104205. Available online: https:/ / www.sciencedirect.com/science/article/pii/S0950423020304927 (accessed on 5 November 2020). [CrossRef]

18. Usanov, D.; van de Ven, P.M.; van der Mei, R.D. Dispatching fire trucks under stochastic driving times, Netherlands. Comput. Oper. Res. 2020, 114, 104829. [CrossRef]

19. Pavelka, K.; Faltýnová, M.; Švec, Z.; Dušánek, P. Mobile Laser Scanning, 1st ed.; CTU in Prague: Prague, Czech Republic, 2014; ISBN 978-80-01-05261-7.

20. AGISOFT LLC. Agisoft Metashape User Manual: Professional Edition. Version 1.7.0. 2020. Available online: https://www. agisoft.com/pdf/metashape-pro_1_7_en.pdf (accessed on 15 July 2021).

21. Transport Research Centre. Swept Paths for Verifying the Passability of Road Elements, 1st ed.; Ministerstvo Dopravy České Republiky: Prague, Czech Republic, 2004; ISBN 80-86502-14-7.

22. REIF. Automotive Handbook, 9th ed.; Konrad a Karl-Heinz DIETSCHE, Revised and Extended; Robert Bosch: Karlsruhe, Germany, 2014; ISBN 978-1-119-03294-6.

23. Lourenço, M.; Oliveira, L.B.; Oliveira, J.P.; Mora, A.; Oliveira, H.; Santos, R. An Integrated Decision Support System for Improving Wildfire Suppression Management. ISPRS Int. J. Geo-Inf. 2021, 10, 497. Available online: https://www.mdpi.com/2220-9964/10 /8/497/htm (accessed on 5 November 2020). [CrossRef]

24. Hussein, T.M.; Erol-Kantarci, M.; Rehmani, M.H. (Eds.) Transportation and Power Grid in Smart Cities, 1st ed.; Wiley: Hoboken, NJ, USA, 2019; ISBN 978-1-119-36008-7.

25. Unmanned Aircraft—Civil Aviation Authority. Civil Aviation Authority—Safe and Sighted [Online]. Copyright @ 2021 All Rights Reserved. Available online: https://www.caa.cz/en/flight-operations/unmanned-aircraft/ (accessed on 30 August 2021).

26. Cureton, P. Drone Futures, UAS in Landscape and Urban Design, 1st ed.; Routledge: Oxfordshire, UK, 2020 ; ISBN 9780815380511.

27. Multi-Use UAV Docking Station Systems and Methods. U.S. Patent 9,387,928 B1, 12 July 2016. 